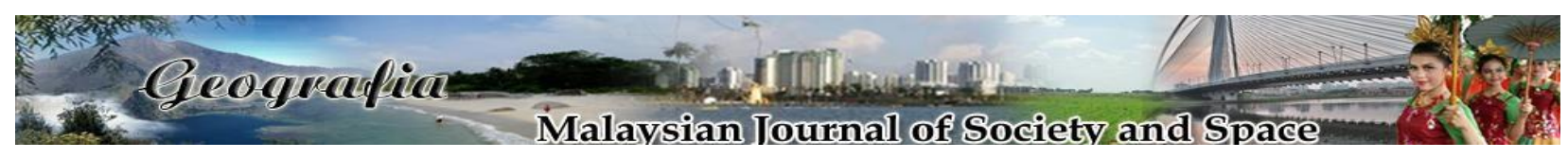

\title{
Mukim Slim: Tapak pelancongan bersejarah di Perak
}

\author{
Nazirah Lee ${ }^{1}$, Rabaah Abdullah ${ }^{1}$, Wan Noorlizawati Wan Mat Ali ${ }^{1}$, Siti Zahrah Mahfood ${ }^{1}$, \\ Mazdi Marzuki² \\ ${ }^{1}$ Jabatan Sejarah, Fakulti Sains Kemanusiaan, \\ Universiti Pendidikan Sultan Idris \\ 2 Jabatan Geografi dan Alam Sekitar, Fakulti Sains Kemanusiaan, \\ Universiti Pendidikan Sultan Idris \\ Correspondence: Nazirah Lee (email: nazirah@fsk.upsi.edu.my)
}

Received: 25 May 2020; Accepted: 16 February 2021; Published: 29 May 2021

\begin{abstract}
Abstrak
Mukim Slim adalah sebahagian daripada daerah Muallim yang terletak di selatan Perak. Ia merupakan destinasi yang ideal untuk dibangunkan sebagai tapak pelancongan bersejarah. Mukim Slim mempunyai berbagai lokasi bersejarah yang usianya menjangkau ribuan tahun, daripada pra sejarah sehinggalah kepada zaman penjajahan British. Kajian ini dijalankan berasaskan kepada kaedah kualitatif. Sumber primer dan sekunder diteliti daripada koleksi institusi seperti Arkib Negara Malaysia dan Muzium Perak. Selain itu, sumber primer juga diperolehi daripada laman sesawang. Hasil kajian mendapati, mukim Slim merupakan pusat kegiatan ekonomi masyarakat Melayu sebelum abad ke-19. Semasa Perang Dunia Kedua, mukim Slim adalah lokasi pertempuran terpenting di antara pihak British dan Jepun kerana "Perang Slim River" yang menentukan siapakah yang akan memenangi perang tersebut berlaku di sini. Jelasnya, latar belakang sejarah dan peristiwa yang berlaku di mukim Slim menyebabkan ia mempunyai potensi untuk dimajukan sebagai tapak pelancongan bersejarah di Perak. Namun begitu, kajian ini juga mendapati pelancongan bersejarah masih belum diberikan perhatian sepenuhnya di mukim Slim. Sehubungan itu, kerjasama bersepadu di antara semua pihak adalah perlu bagi menyemarakkan sektor pelancongan bersejarah di mukim Slim. Ia penting kerana pemerkasaan aktiviti pelancongan bersejarah akan membantu meningkatkan ekonomi setempat dan mempelbagaikan destinasi pelancongan di Perak sebagaimana yang dihasratkan oleh kerajaan negeri tersebut.
\end{abstract}

Kata kunci: Laluan Mat Kilau, Mukim Slim, pelancongan bersejarah, perang dunia kedua, Perak, Tasik YDP 


\title{
Sub-district of Slim: A historical based tourism site in Perak
}

\begin{abstract}
Sub-district of Slim is a part of Muallim district and located in the southern part of Perak. It is indeed an ideal destination to be developed as a historical based tourism site. The argument came from the existence of various interesting historical sites spanning thousand years back to the pre historic period up until the British colonialization. This study is conducted based on the qualitative method. Primary and secondary sources were consulted at the National Archives of Malaysia and the Museum of Perak. Primary sources were also obtained from websites. Documents consulted suggest that the sub-district of Slim was the heart of the Malays' economic activities prior to the nineteenth century. During the Second World War, it was the most important location for the British and Japanese as the Battle of Slim River occurred here was seen as a benchmark to determine the result of warfare in Malaya. Evidently, remarkable historical events unfolded in the sub-district of Slim enhance its potential to be developed as a historical based tourism site in Perak. Nevertheless, this study also found that the historical based tourism has not yet been in the highlights in the sub-district of Slim. Therefore, collective actions required from all parties involved in ensuring historical based tourism materialize in the sub-district of Slim. The increase of tourism activities would serve as a stepping stone to boost local economy and help to realise Perak governments' aim to diversify tourist destination in the state.
\end{abstract}

Keywords: Trail of Mat Kilau, sub-districts Slim, historical based tourism, Second World War, Perak, YDP Lake.

\section{Pengenalan}

Wabak Covid-19 memberi kesan besar kepada ekonomi negara khususnya dalam sektor pelancongan. Justeru, sebagai persediaan untuk tempoh pasca covid, pengenalan lokasi baharu pelancongan adalah perlu sebagai langkah untuk mempelbagaikan produk pelancongan sedia ada bagi membantu melonjakkan semula pembangunan ekonomi. Makalah ini mengetengahkan mukim Slim sebagai lokasi pelancongan bersejarah baharu di Selatan Perak. Ini kerana pelancongan warisan adalah salah satu produk pelancongan yang menyumbang dalam penjanaan ekonomi di Malaysia (Zuliskandar Ramli et al., 2015). Mukim Slim berpotensi besar sebagai destinasi pelancongan bersejarah kerana kekayaan sejarahnya, khususnya di sepanjang abad ke-19 dan ke-20. Promosi pelancongan di mukim Slim yang dijalankan sebelum ini tidak mengetengahkan latar belakang sejarahnya yang berpotensi untuk menarik minat pelancong untuk berkunjung ke lokasi berkenaan. Makalah ini membincangkan sejarah mukim Slim pada abad ke19 dan ke-20 untuk memperlihatkan kepentingan dan keunikannya dalam sejarah Malaysia dan seterusnya mengangkat kawasan berkenaan sebagai salah satu produk pelancongan bersejarah di selatan Perak. Ini kerana potensi sesebuah lokasi untuk dijadikan sebagai kawasan pelancongan bersejarah meningkat jika disandarkan kepada latar belakang sejarahnya (Siti Norsakira Mohamad \& Rosniza Azmie Che Ros, 2018). Secara umumnya, kejayaan produk pelancongan bergantung kepada beberapa faktor. Antaranya, keunikan dan keistimewaan yang membawa persepsi positif kepada pelancong sesebuah lokasi (Hamzah Jusoh et al., 2014). Ia juga bergantung kepada peranan 
pihak berkuasa yang bertanggungjawab merangka pelan yang strategik dan promosi yang baik kepada sesebuah destinasi pelancongan (Mastura Jaafar et al., 2015a).

\section{Sorotan literatur}

Pelancongan warisan menyumbang kepada peningkatan ekonomi dan ia merupakan pelancongan utama di Eropah khususnya di negara seperti Itali, Sepanyol, Perancis. Selain itu, di United Kingdom, pelancong antarabangsa yang berkunjung ke destinasi pelancongan warisan membelanjakan sebanyak $£ 17.5$ juta pada 2015. Sehubungan itu pelancongan warisan dianggap sektor penting di negara berkenaan (Oxford Economics, 2016). Sumbangannya yang lumayan dalam bidang ekonomi menyebabkan pelancongan warisan diberi keutamaan di Malaysia. Kewujudan tapak pelancongan bersejarah berupaya meningkatkan kualiti hidup masyarakat setempat melalui peluang pekerjaan dalam sektor pelancongan dan peningkatan kemudahan dan insfrastruktur setempat. Selain itu, pelancongan warisan juga melonjakkan perasaan bangga penduduk terhadap tempat asal mereka (Mastura Jaafar et al., 2015b).

Di negeri Perak, pelancongan adalah penyumbang ketiga terbesar dalam ekonomi negeri selepas sektor pembuatan dan pertanian (Ucapan Bajet 2017, Negeri Perak). Oleh itu, kerajaan komited untuk mempelbagaikan produk pelancongan di negeri berkenaan dalam usaha untuk mengukuhkan ekonominya. Ia meliputi usaha untuk meluaskan premis pelancongan, penyediaan pemandu pelancong yang berkebolehan dan penginapan yang unik kepada pelancong (Negeri Perak, 2016). Komitmen tinggi kerajaan negeri Perak terbukti melalui jumlah pelancong domestik tertinggi yang dicatatkan di negeri berkenaan sejak 2012-2015. Perak juga telah memperolehi anugerah emas bagi kategori Destinasi Pilihan daripada Malaysian Tourism Council pada 2017. Bajet Negeri Perak (2017) mencatatkan bahawa kerajaan negeri memperuntukkan sebanyak RM10 juta untuk sektor berkenaan. Jelasnya, Perak memberikan perhatian besar kepada sektor pelancongan.

Salah satu produk pelancongan yang berpotensi untuk dikembangkan di Perak adalah pelancongan bersejarah. Di Malaysia pelancongan warisan dan kawasan bersejarah merujuk kepada lima buah bandar iaitu Melaka, Georgetown, Kota Bahru, Ipoh dan Taiping (Lee et al., 2013).Terdapat dua bandar iaitu Taiping dan Ipoh telah dipromosikan sebagai destinasi pelancongan berasaskan warisan di Perak. Selari dengan itu, kerajaan negeri memberikan tumpuan kepada usaha pemeliharaan dan pemuliharaan bangunan warisan di kedua-dua bandar ini (Negeri Perak, 2016). Kejayaan sektor pelancongan di kedua-dua bandar ini juga boleh dilihat daripada statistik pelawat yang mengunjungi bandar berkenaan seperti mana yang dilaporkan oleh Jabatan Muzium Malaysia. Pada 2018, terdapat 245,984 pelancong yang mengunjungi muzium yang terletak di bandar Taiping (Jabatan Muzium Malaysia, 2018, 21). Faktor yang menarik pelancong ke lokasi adalah senibina, pameran, acara dan aktiviti yang dianjurkan di lokasi pelancongan. Perhatian khusus kepada tapak bersejarah di Perak dapat dilihat melalui penyenaraian aset warisan yang berpotensi di negeri berkenaan mengikut daerah sepertimana yang terdapat dalam jadual 1 .

Jadual 1 memperlihatkan bahawa aset warisan dan potensi kawasan Muallim sebagai produk pelancongan warisan masih belum diberi perhatian oleh kerajaan negeri Perak kerana ia tidak disenaraikan dalam senarai tersebut. Ia boleh dianggap sebagai fenomena umum di Perak. Brosur pelancongan yang disediakan oleh Perak Tourism yang bertajuk Perak Guidebook (2019) hanya merujuk Muallim sebagai daerah yang penting dalam sejarah pendidikan. Manakala dalam bahagian "warisan" Perak Tourism (2021, Heritage) menyenaraikan lapan Laluan Warisan di 
Perak yang berada di luar kawasan Muallim. Selain itu, carian di laman sesawang berkenaan menyatakan tiada lokasi pelancongan berasaskan warisan di Muallim (Ibid). Keadaan ini mungkin berpunca daripada kedudukan Muallim sebagai daerah yang baharu sahaja diisytiharkan di negeri Perak pada 2016. Sehubungan itu, potensinya dalam sektor pelancongan masih belum diberi perhatian.

Jadual 1. Senarai aset warisan yang berpotensi di setiap daerah.

\begin{tabular}{lc}
\hline Nama Daerah & Jumlah \\
\hline Kuala Kangsar & 8 \\
Larut Matang dan Selama & 10 \\
Hilir Perak & 2 \\
Hulu Perak & 8 \\
Kinta & 19 \\
Kampar & 6 \\
Manjung & 1 \\
Batang Padang & 4 \\
Perak Tengah & 2 \\
\hline
\end{tabular}

Sumber: Negeri Perak (2016)

Kajian terdahulu memperlihatkan kekayaan dan kepelbagaian sejarah mukim Slim (Leech, 1879; Swettenham, 1880; Nazirah Lee, 2018). Dari sudut sejarah politiknya, Slim dan Bernam merupakan kawasan yang menyaksikan pertikaian dan perebutan kuasa di antara Perak dan Selangor (Gullick, 2010). Semasa penjajahan British ia diletakkan dalam daerah Batang Padang. Bagaimanapun, mulai 2016 mukim Slim diletakkan di dalam daerah Muallim dan bandar Slim River berfungsi sebagai pusat pentadbiran daerah tersebut (Pejabat Tanah dan Daerah Muallim, 2016). Slim River merupakan laluan utama daripada kawasan utara untuk ke Kuala Lumpur. Lantaran itu, British membina jalan raya bagi menghubungkan Slim River dengan Tanjong Malim dan ia siap dibina sepenuhnya seawal tahun 1899 (Report on the Batang Padang District for the year 1899). Jalan tersebut menjadi laluan utama yang menghubungkan kawasan utara, tengah dan selatan di Semenanjung Malaysia.

Kedudukan yang terletak di tengah-tengah Semenanjung menjadikan mukim Slim dianggap sebagai lokasi penting dalam mempertahankan kedudukan British di Semenanjung semasa Perang Dunia Kedua (PD2). Mukim Slim memainkan peranan sebagai benteng akhir untuk menghalang kemaraan Jepun ke Kuala Lumpur dan seterusnya ke Singapura. Pertempuran yang dikenali sebagai "Perang Slim River" tercetus di mukim Slim. Ia dianggap sebagai kawasan terpenting dalam proses British mempertahankan kuasanya di Tanah Melayu. Kekalahan British dalam pertempuran ini menyediakan laluan mudah kepada pihak Jepun untuk mengambil alih kuasa di Malaya (Warren, 2002).

Berhubung zaman pra sejarah, Bulletin of the Raffles Museum terbitan Disember 1937 menyatakan bahawa mukim Slim mempunyai tiga buah kubur kepingan batu yang mempunyai ratusan manik, peralatan tembikar dan lain-lain (Winstedt, 1941). Rangkaian kubur kepingan batu yang disahkan bertarikh seawal zaman logam ditemui di Kampung Slim (Adi Taha 1987; Yunus Sauman \& Wan Noorlizawati, 2010). Ia memperlihatkan mukim Slim adalah kawasan yang mempunyai sejarah yang sangat panjang sehingga menjangkaui zaman pra-sejarah.

Sementara itu, kajian berhubung sejarah kawasan Muallim memperlihatkan kedudukan mukim Slim yang penting dalam rangkaian dan jaringan ekonomi masyarakat Melayu di Perak, Pahang dan Selangor sebelum kedatangan British (Nazirah Lee, 2018). Catatan Leech (1879) yang melalui mukim Slim dalam perjalanannya ke Pahang pada awal abad ke-20 menggambarkan 
mukim Slim sebagai sebuah kawasan perkampungan yang mempunyai kawasan penanaman padi yang luas. Kepentingan mukim Slim dalam bidang pertanian musnah ekoran daripada kegiatan bijih timah yang dijalankan oleh syarikat Perancis yang dikenali sebagai Southern Kinta Company (SKC) (Nathan, 1915). Kegiatan perlombongan bijih timah di mukim Slim ini bermula pada suku terakhir abad ke 19 dan dihentikan seketika pada tahun 1898 (Report on Tanjong Malim District, 1898). Namun begitu, operasinya diteruskan pada tahun berikutnya di bawah seliaan Mr. Irving dan Mansiuer Bonnefund (Perak Government Gazette, February 1899). Jelasnya, mukim Slim mempunyai latar belakang sejarah yang menarik sejak daripada zaman pra sejarah sehingga abad ke-20.

Walaupun potensi mukim Slim dalam pelancongan bersejarah masih belum diberikan perhatian, kerajaan Perak dalam pelan pembangunan pelancongannya mengisytiharkan beberapa lokasi yang akan dimajukan sebagai pusat pelancongan berasaskan rekreasi di sepanjang laluan Electric Train Service (ETS) di Slim River. Ia termasuklah Sungai Bil, Sungai Ulu Slim dan Kolam Air panas di Ulu Slim (Negeri Perak, 2016). Lokasi berkenaan telah pun mendapat perhatian daripada pelancong domestik dan antarabangsa. Arung Jeram Sungai Ulu Slim sebagai contohnya menyediakan aktiviti rekreasi mencabar yang mendapat sambutan menggalakkan daripada pelancong antarabangsa (Majlis Daerah Tanjong Malim, 2020). Ringkasnya, sektor pelancongan berasaskan rekreasi mendapat perhatian daripada kerajaan negeri Perak berbanding pelancongan berasaskan sejarah.

\section{Metod dan kawasan kajian}

Kajian kualitatif ini dijalankan berasaskan kepada kaedah penyelidikan sejarah. Perbincangan berasaskan kepada maklumat yang diperolehi daripada sumber primer dan sumber sekunder. Antara sumber primer yang digunakan adalah rekod, fail dan laporan pentadbiran British yang diperolehi daripada Arkib Negara Malaysia, Kuala Lumpur dan juga Muzium Perak, Taiping. Laporan pegawai British berhubung kawasan di mukim Slim, Hulu Perak dan Jalan Penarikan yang berkait dengan mukim Slim juga yang diperolehi daripada Journal of Royal Asiatic Society dan kebanyakannya diterbitkan pada penghujung abad ke-19. Selain itu, sumber primer khususnya laporan kerajaan negeri Perak dan laporan tahunan diperolehi di atas talian. Di samping itu maklumat berhubung pelancongan di mukim Slim dan daerah Muallim diperolehi daripada laman sesawang. Maklumat disaring dan dianalisis kesahihannya melalui rujukan silang kepada maklumat daripada dokumen lain. Penulis turut menggunakan akhbar yang diterbitkan secara atas talian daripada Trove dan akhbar lama yang terdapat dalam koleksi Arkib Negara Malaysia dan Muzium Perak. Sumber sekunder seperti buku dan jurnal diperolehi dari perpustakaan Universiti Pendidikan Sultan Idris. Kajian ini menumpukan kepada mukim Slim yang terletak di daerah Muallim (Rajah 1). Catatan daripada penerokaan yang dijalankan oleh pegawai British pada 1879 menyatakan kawasan ini merupakan tanah tinggi dengan ketinggian sekitar 600-700 kaki daripada aras laut (Deane, 1879). Mukim Slim semasa pentadbiran British diletakkan di bawah pentadbiran Batang Padang yang termasuk dalam mukim Ulu Bernam bersama-sama Tanjong Malim (Badriyah Salleh, 1985). Dari sudut lokasinya, mukim Slim terletak $100 \mathrm{~km}$ daripada Kuala Lumpur dan Ipoh (Fong Pek Yee, 2016). Ia dihubungkan dengan bandar utama melalui jalan raya dan keretapi. Jelasnya, ketersampaian ke mukim Slim adalah mudah sama ada melalui pengangkutan awam atau pun kenderaan persendirian. 


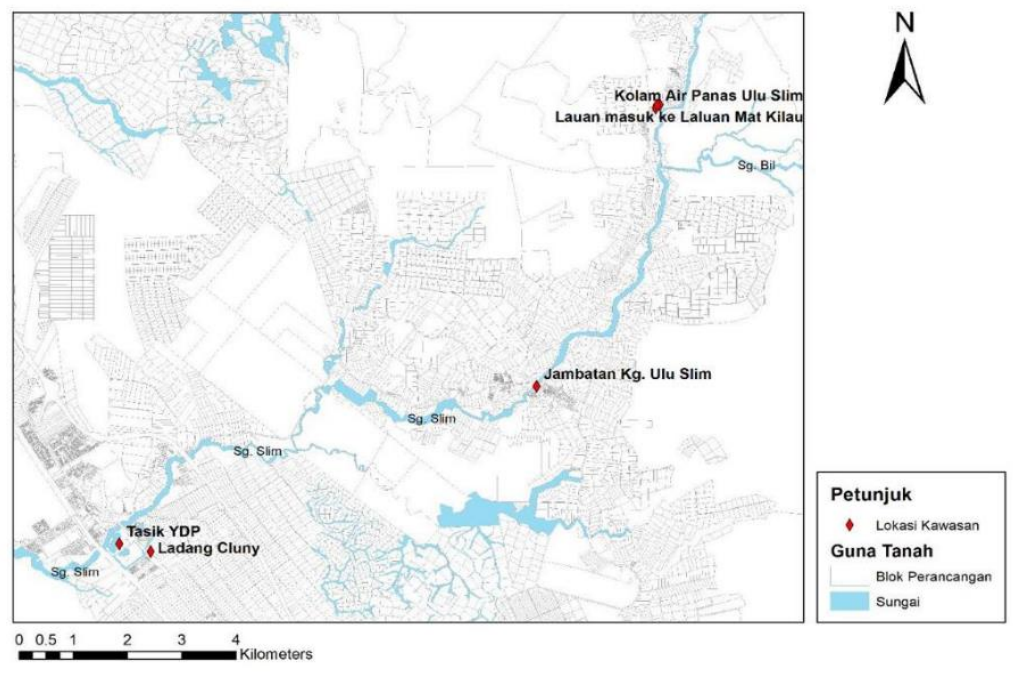

Rajah 1. Lokasi kajian

\section{Hasil kajian}

\section{Latar belakang sejarah}

\section{a. Laluan perdagangan dan tapak arkeologi}

Mukim Slim terletak di laluan perdagangan yang penting di Negeri-negeri Melayu. Pada suku terakhir abad ke-19, pegawai British memberi perhatian khusus kepada kawasan ini kerana mereka beranggapan ia kaya dengan hasil bumi khususnya bijih timah dan emas. Ekoran daripada kepentingan dan potensi ekonominya, pegawai British menggelarkan kawasan ini sebagai "Pintu Gerbang Selatan" negeri Perak (Swettenham, 1893:30). Pegawai British, Leech (1879) sebagai contohnya mencatatkan tentang penduduk dan kegiatan perdagangan mereka melalui jalan darat dan jalan sungai. Leech merekodkan bahawa kegiatan ekonomi di Slim dan Bernam berpusat di dua buah sungai iaitu Sungai Slim dan Sungai Bernam. Sungai Slim memainkan peranan sebagai laluan kepada perdagangan merentas negeri di pantai Barat dan Pantai Timur. Manakala, sungai Bernam pula berfungsi sebagai laluan kepada para pedagang untuk ke Selat Melaka sebelum mereka meneruskan kegiatan perdagangan di Singapura atau Pulau Pinang.

Sementara itu, laluan darat dikenali sebagai Laluan Mat Kilau atau Jalan Penarikan, bermula di Ulu Slim dan berakhir di Ulu Sungai, Raub Pahang. Bradell (1937), sebagai contohnya menyatakan bahawa pedagang emas daripada Ulu Jelai (Pahang) seringkali menggunakan jalan di Ulu Sungkai dan Ulu Slim. Kawasan dan lokasi yang dilalui oleh para pedagang di Laluan Mat Kilau dicatatkan oleh Swettenham dalam laporannya berhubung perjalanan merentas Semenanjung pada 1885. Laluan yang lazim digunakan setelah melalui Sungai Bernam adalah Kuala Slim ke Kuala Geliting, Briseh, Sapor Batu, Batu Hidang, Batu Gajah, Sungai Sembilan, Lipis dan seterusnya ke Jelai (Swettenham, 1885: 58). Ringkasnya, mukim Slim adalah permulaan kepada laluan yang digunakan untuk merentas daripada kawasan barat ke Timur Semenanjung Tanah Melayu. Jalan ini juga menyediakan akses kepada negeri Pahang. Justeru, pegawai British (contohnya, Frank Swenntenham dan Hugh Clifford) yang cuba menjalinkan hubungan dengan 
Sultan Pahang, sebelum dan selepas dimeterinya Perjanjian Pahang 1887 menggunakan jalan tersebut sebagai laluan dalam perjalanan mereka untuk ke Pekan Pahang (Windstedt, 1935: 245).

Laluan Mat Kilau digunakan oleh pedagang emas daripada Pahang untuk ke Perak. Permintaan tinggi kepada emas Pahang di Perak adalah disebabkan oleh warnanya yang lebih berkualiti dan menarik. Sementara itu, hasil bijih timah dan padi yang ditanam di mukim Slim dijual ke Pahang (F.M.S. should survey Slim River Valley, 1938, April 17,2). Permintaan tinggi terhadap beras yang dibawa daripada Slim di Pahang adalah disebabkan beras tersebut terkenal sebagai berkualiti tinggi. Badriyah Salleh (1985) menyatakan bahawa permintaan tinggi tersebut didorong oleh tanggapan masyarakat ketika itu yang mengatakan bahawa beras keluaran petani di mukim Slim mempunyai rasa yang lebih lazat berbanding kawasan lain (Ibid).

Sejarah mukim Slim juga boleh dikesan sehingga zaman pra-sejarah. Laporan akhbar The Straits Times pada April 1938 sebagai contohnya adalah tentang gesaan kepada kerajaan Negerinegeri Melayu Bersekutu untuk menjalankan tinjauan dan kajian di Lembah Slim River (F.M.S. should survey Slim River Valley, 1938, April 17,2). Ini kerana terdapat pelbagai laporan mengenai penemuan relik yang menunjukkan kewujudan tamadun awal (Ibid). Salah satu daripada tapak arkeologi di mukim Slim adalah Kubur Kepingan Batu yang turut dijumpai di Sungkai dan Changkat Menteri (Wilkinson, 1939). Sarjana percaya kewujudan kubur ini membuktikan bahawa kawasan berkenaan adalah pintu masuk utama ke selatan Perak. Catatan dan tulisan para pegawai British yang dinyatakan di atas memperlihatkan bahawa mukim Slim mempunyai latar belakang sejarah yang panjang. Kajian mendapati bahawa kubur kepingan batu yang dijumpai di kawasan mukim Slim ini ditarikhkan pada abad ke-4 sebelum Masihi. Manakala manik kaca dan manik carnelian yang ditemui di dalam kubur berkenaan berkemungkinan dibawa daripada Mesir atau Afrika Selatan atau Filipina.

Ringkasnya sejarah mukim Slim sebelum kedatangan dan penjajahan Brititsh adalah manifestasi kepada kerancakan kegiatan ekonomi masyarakat Melayu tradisional di Pantai Barat dan Pantai Timur Semenanjung Tanah Melayu. Manakala laporan arkeologi memperlihatkan bahawa adanya kegiatan dan kedatangan masyarakat antarabangsa. Jelasnya, mukim Slim merupakan kawasan yang menyimpan sejarah keterlibatan masyarakat Melayu tradisional dalam hal ehwal perdagangan sebelum kedatangan British. Ia merupakan mukim yang menyimpan sejarah yang membuktikan pembabitan masyarakat Melayu dalam kegiatan ekonomi dan keaktifan mereka dalam sektor berkenaan. Sejarah mukim Slim memperlihatkan bahawa masyarakat Melayu aktif dalam dunia komersil sebelum mereka terperangkap dan terpinggir dalam dunia ekonomi yang dibentuk berasaskan kepada polisi British. Jelasnya, promosi kepada perkembangan sejarah ini akan memperlihatkan satu sisi baharu dalam perkembangan sosio-ekonomi masyarakat Melayu sebelum kedatangan British.

\section{b. Lokasi penting Perang Dunia Kedua}

Penjajahan Jepun di Tanah Melayu bermula di Kota Bharu, Kelantan pada penghujung 1941. Jepun seterusnya menawan kawasan Pantai Timur dan Utara Semenanjung. Dalam usaha untuk mara dan menawan Singapura, terdapat sebuah pertempuran yang dianggap sebagai penentu nasib Jepun dan British di Tanah Melayu. Ia dikenali sebagai Perang Slim River yang berlaku pada 9 Januari 1942 di mukim Slim dan lokasi terjadinya pertempuran berkenaan ditunjukkan dalam rajah 2 . 


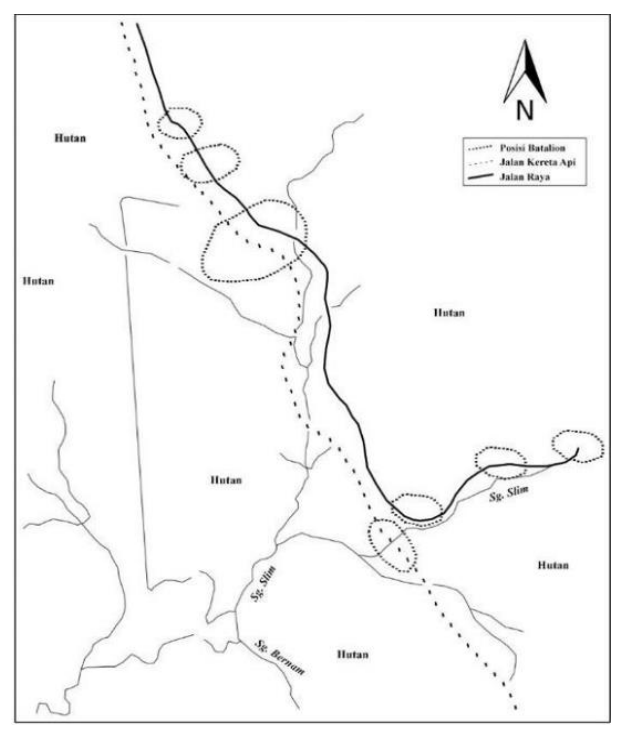

Rajah 2. Posisi batalion British dalam Perang Slim River, 1942 di Mukim Slim.

"Perang Slim River" menyaksikan pertempuran yang sengit di antara kedua-dua pihak dan menyebabkan ramai tentera terkorban. Pihak Jepun menganggap jumlah kematian yang tinggi sebagai elemen penting yang menaikkan semangat juang tentera Jepun di Tanah Melayu (Chinese press praises Nipponese army, 1942 Febuari 26). Manakala di pihak British, ia adalah petanda buruk kepada mereka. Mayborough Chronicle melaporkan tentera British berundur sehingga ke Rawang, Selangor dan memilih untuk bersembunyi di hutan demi menyelamatkan diri. Mereka juga meninggalkan senjata dan kenderaan kerana serangan bertalu-talu pihak Jepun yang menyebabkan ramai dalam kalangan mereka menemui maut (Slim River Battle, 1942 Januari 12). British gagal melawan Jepun kerana mereka menggunakan kereta kebal dan lori serta tentera pejalan kaki untuk menyerang kawasan-kawasan yang strategik di Slim River (Japs using heavier tanks, 1942 January 10). Namun begitu, pihak British tetap meneruskan propaganda di media bagi memperlihatkan bahawa mereka masih mampu bertahan di Tanah Melayu. Sebagai contohnya, pihak British menegaskan bahawa kejayaan pihak Jepun di Slim River hanyalah disebabkan keputusan mereka dan bukanlah disebabkan kelemahan tentera British (Enemy infiltration in Selangor, 1942 Januari 9). Dalam usaha untuk menjustifikasikan tindakan mereka, British menyatakan bahawa penguasaan Slim River tidak penting dan pendudukan Jepun di kawasan berkenaan tidak akan menggugat kekuasaan British di Tanjong Malim (Ibid).

Jepun menganggap bahawa penguasaan mereka kepada kawasan Slim River adalah jaminan kejayaan kepada rancangan mereka bagi menakluki Tanah Melayu. Syonan Shimbun pada Ogos 1942 melaporkan bahawa penguasaan Slim River membolehkan Jepun untuk menguasai Kuala Lumpur tanpa sebarang tentangan (Memorial to our fallen heroes, 1942 Ogos 22). Perhatian khusus pihak pentadbiran Jepun di Tanah Melayu kepada Slim River boleh dilihat kepada peruntukan besar yang diberikan untuk proses pembaik pulihan infrastruktur di kawasan berkenaan. Laporan oleh Syonan Shimbun pada September 1942 menyatakan bahawa kerajaan nengeri memperuntukkan sebanyak $\$ 2,000,000$ bagi memperbaiki jalan raya yang berfungsi sebagai jalan utama menghubungkan Slim River dengan Tanjong Malim. Selain itu, peruntukan tersebut juga disalurkan untuk pembinaan jalam raya di Slim untuk ke Malim Nawar, Tanjong Tualang, Simpang Ampat dan Kampung Ijok (\$3,500,000 to be spent 291942 September 3). Jelasnya, mukim Slim dianggap sebagai kawasan yang penting dalam pentadbiran Jepun di Tanah 
Melayu. Ringkasnya, mukim Slim menyimpan sejarah berhubung persaingan di antara British dan Jepun semasa PD2. Perincian berhubung lokasi pertempuran ini akan memberikan kesedaran dan meningkatkan perasaan patriotisme dalam kalangan pelancong domestik.

\section{Potensi dan cabaran}

Mukim Slim berpotensi diketengahkan sebagai lokasi pelancongan bersejarah. Penemuan rangkaian kubur kepingan batu di lokasi berkenaan memperlihatkan kepentingan mukim Slim dalam sejarah perkembangan masyarakat di Semenanjung Tanah Melayu. Selain itu, ia merupakan laluan penting dalam rangkaian perdagangan emas, bijih timah dan hasil hutan sebelum penjajahan British. Selanjutnya, mukim Slim juga merupakan tapak pertempuran yang menentukan kemenangan di antara Jepun dan Britain dalam PD2 di Tanah Melayu. Kekuatan mukim Slim sebagai lokasi pelancongan bersejarah juga boleh disandarkan kepada kepelbagaian jenis aktiviti yang boleh dilakukan oleh pelancong yang berkunjung tapak bersejarah berkenaan. Laluan Mat Kilau sebagai contohnya sesuai untuk dimajukan sebagai lokasi pelancongan bersejarah yang menawarkan aktiviti lasak seperti jungle trekking. Pelancong berpeluang menyelusuri jalan hutan yang menghubungkan Perak dan Pahang. Selain itu, pelancong yang berminat dengan aktiviti lasak juga berpeluang meneroka jeram-jeram di sungai Slim dengan mengikuti aktiviti water rafting di sepanjang sungai berkenaan. Sementara itu, bagi peminat alam semula jadi, aktiviti berkelah boleh dilakukan di beberapa lokasi perkelahan di mukim Slim dan mukim Hulu Bernam Timur yang terletak berhampiran.

Selanjutnya, tapak bersejarah di mukim Slim juga berpotensi sebagai destinasi pelancongan pendidikan kepada pelajar sekolah atau institusi pengajian tinggi (IPT). Dokumen Standard Kurikulum dan Pentaksiran (DSKP) yang diperkenalkan untuk subjek sejarah di peringkat sekolah menengah memberikan penekanan kepada beberapa cara pembelajaran baharu yang sesuai dengan abad ke-21. Antaranya adalah Pembelajaran Luar Bilik Darjah (PLBD) dan kajian kes. Lokasi bersejarah di mukim Slim mempunyai ciri-ciri yang sesuai dan boleh digunakan dalam kedua-dua elemen tersebut kerana latar belakang sejarahnya yang bermula sejak daripada zaman pra-sejarah sehinggalah kepada PD2. Secara umumnya, perkembangan dalam zaman tersebut adalah sebahagian daripada tajuk dan tema yang termasuk dalam kurikulum sejarah bagi pelajar yang berada di tingkatan satu sehingga tingkatan empat sebagaimana yang diringkaskan dalam jadual 2.

Jadual 2: Kurikulum sejarah tingkatan 1 hingga tingkatan 4.

\begin{tabular}{|c|c|c|}
\hline Tingkatan & Tajuk/Tema & Lokasi \\
\hline 1 & Zaman Pra Sejarah & $\begin{array}{l}\text { Changkat Menteri; } \\
\text { Kampung Ulu Slim }\end{array}$ \\
\hline 2 & $\begin{array}{l}\text { Alam Melayu } \\
\text { Tajuk lima berkenaan kesultanan Melayu di Perak, Pahang, } \\
\text { Selangor dan Trengganu. }\end{array}$ & $\begin{array}{l}\text { Kampung Ulu Slim; } \\
\text { Laluan Mat Kilau }\end{array}$ \\
\hline 3 & $\begin{array}{l}\text { Kedatangan Kuasa Barat } \\
\text { Pentadbiran Negeri Melayu Bersekutu } \\
\quad \quad \quad \text { Kekayaan hasil bumi }\end{array}$ & $\begin{array}{c}\text { Laluan Mat Kilau } \\
\text { Tasik YDP Slim River }\end{array}$ \\
\hline 4 & $\begin{aligned} \text { Warisan Negara Bangsa } \\
-\quad \text { Perjuangan rakyat kepada kemerdekaan } \\
-\quad \text { PD2 } \\
-\quad \text { Zaman Jepun }\end{aligned}$ & $\begin{array}{c}\text { Kampung Slim Village, } \\
\text { Ladang Cluny }\end{array}$ \\
\hline
\end{tabular}

Sumber: Dokumen Standard Kurikulum dan Pentaksiran (DSKP) Sejarah, 2018; (DSKP) Sejarah, 2017; (DSKP) Sejarah, 2016; (DSKP) Sejarah, 2015 
Perbincangan di atas menunjukkan lokasi bersejarah di mukim Slim berpotensi dimajukan kerana pelancong berpeluang mengunjungi pelbagai lokasi dan melakukan berbagai-bagai aktiviti. Jarak mukim Slim yang hampir dengan destinasi pelancongan lain seperti Ipoh, Kuala Lumpur, Bukit Fraser, Genting Highlands dan Cameron Highlands juga meningkatkan potensinya untuk dimajukan sebagai lokasi pelancongan baharu. Justeru, mukim Slim boleh dipasarkan kepada pelancong domestik dan antarabangsa kerana destinasi pelancongan di atas popular di dalam dan di luar negara. Dari sudut ketersampaiannya, pelancong yang ingin berkunjung ke mukim Slim mempunyai pelbagai pilihan kerana ia dihubungkan melalui jalan raya dan jalan kereta api. Pengguna yang memilih untuk datang dengan kenderaan persendirian boleh menggunakan Lebuh Raya Utara Selatan ataupun jalan negeri. Perkhidmatan pengangkutan awam seperti bas, kereta api dan teksi juga boleh didapati di mukim ini.

Potensi mukim Slim sebagai destinasi pelancongan baharu di selatan Perak juga disokong oleh lokasi lain yang terdapat di daerah Muallim. Sebagai contohnya, Laluan Warisan dan Muzium Pendidikan Nasional di Universiti Pendidikan Sultan Idris (UPSI) yang menawarkan lokasi bersejarah yang signifikan dalam perkembangan dunia pendidikan di Malaysia. Muallim juga mempunyai pelbagai lokasi bersejarah yang lain. Misalnya, Kampung Kubu; penempatan masyarakat Rawa selepas terlibat dalam perang di Pahang pada abad ke-19, rumah tokoh nasionalis, Ahmad Boestamam di Behrang, Bukit Changkat Asa yang menyimpan sejarah zaman darurat di Tanjong Malim pada 1950-an dan lain-lain.

Walau bagaimanapun, terdapat beberapa cabaran dalam usaha mengangkat Mukim Slim sebagai lokasi pelancongan bersejarah di Perak. Promosi berhubung kekayaan sejarah bagi tapak pelancongan bersejarah yang terdapat di mukim Slim masih belum sempurna. Ini dapat dilihat melalui keterbatasan maklumat berkenaan sejarah berhubung lokasi pelancongan yang terdapat di dalam laman sesawang yang mempromosikan pelancongan di Muallim. Sebagai contohnya, Majlis Daerah Tanjong Malim dalam laman sesawang rasminya menyenaraikan "kawasan menarik" di daerah berkenaan seperti Kolam Air Panas Ulu Slim, Taman Pergola Ulu Slim, Tasik Yang Dipertua (YDP) dan Lata Sungai Bil. Namun begitu, tinjauan kepada maklumat yang dipaparkan memperlihatkan bahawa latar belakang sejarah tidak ditonjolkan. Pendekatan sedemikian menyebabkan latar belakang sejarah lokasi berkenaan kurang diketahui oleh masyarakat. Sebagai contohnya Lata Sungai Bil yang terletak di Ulu Slim hanya dipromosikan sebagai lokasi untuk aktiviti keluarga dan aktiviti lasak tanpa mengangkat keunikan Sungai Bil. Dari sudut sejarahnya, Sungai Bil yang berfungsi sebagai kawasan sempadan dan pergolakan politik di antara Selangor dan Perak pada abad ke-19. Konflik sempadan tersebut mempunyai kaitan dengan percaturan politik antarabangsa di antara Siam dan Britain di Negeri-negeri Melayu. Pemaparan maklumat sejarah mampu mengetengahkan keunikan lokasi berkaitan dan menjadi faktor penarik kepada pelancong. Ini kerana elemen sejarah dan warisan memainkan peranan penting dalam pemilihan destinasi dalam kalangan pelancong. Laporan Tahunan 2018, contohnya menunjukkan 36.8 peratus pelancong memilih untuk melawat ke tapak bersejarah di Malaysia (Tourism Malaysia, 2018). Jelasnya, paparan maklumat berhubung keunikan latar belakang sejarah adalah penting dan perlu untuk menarik pelancong ke mukim Slim.

Maklumat sejarah yang tidak lengkap atau dipersembahkan dengan cara yang kurang menarik dalam laman sesawang rasmi akan meninggalkan kesan negatif kepada usaha untuk mengetengahkan mukim Slim sebagai destinasi pelancongan berasaskan sejarah. Contohnya, maklumat berhubung latar belakang sejarah Tasik Yang Dipertua (YDP). Walaupun ia menyatakan dengan jelas bahawa tasik berkenaan berasal daripada lombong tinggal namun, ketiadaan maklumat berhubung pemilik dan perkembangan berkaitan menyebabkan keunikannya 
tidak terserlah. Kekurangan sebegini boleh diatasi dengan menyediakan latar belakang sejarah yang menarik tentang sesebuah lokasi. Tasik YDP sebagai contohnya adalah bekas lombong bijih timah milik SKC yang diusahakan sejak abad ke-19. Kegiatan perlombongan SKC memberi kesan besar kepada landskap dan sektor ekonomi masyarakat di mukim Slim. Ia telah mengubah kualiti air dan menganggu kesinambungan pertanian padi yang diusahakan ketika itu. Akibatnya, pengeluaran padi yang dianggap terbaik dan istimewa di mukim Slim telah terhenti. Maklumat sejarah tentang Tasik YDP membuktikan bahawa pemerintahan kolonial mengubah landskap sosio-ekonomi masyarakat. Ringkasnya, perkongsian maklumat sejarah yang lengkap mampu memperlihatkan latar belakang yang unik yang berpotensi menarik minat pelancong untuk berkunjung ke mukim Slim. Perak adalah lokasi kegemaran pelancong domestik di Malaysia dan berada di kedudukan ketiga di antara negeri-negeri yang menerima paling ramai kunjungan pelancong pada 2018 dengan penerimaan pelancong seramai 7.6 juta orang (Ibid,23). Sehubungan itu, pendedahan maklumat sejarah yang unik berperanan menarik para pelancong untuk berkunjung.

Masalah berhubung kurangnya pendedahan maklumat sejarah berkaitan lokasi pelancongan di mukim Slim boleh diatasi melalui kerjasama antara institusi kerajaan, badan berkanun dan masyarakat tempatan. Perkongsian maklumat sejarah daripada penyelidikan di universiti dan agensi kerajaan boleh membantu mengisi kelompangan yang ada. Latar belakang sejarah berkenaan boleh diketengahkan dengan mengoptimumkan penggunaan media sosial dan aktiviti promosi yang dianjurkan pada peringkat daerah, negeri mahu pun negara.

Seterusnya, cabaran terbesar adalah kurangnya perhatian kepada lokasi pelancongan bersejarah di mukim Slim. Cerapan kepada laman sesawang serta akaun facebook dan youtube memperlihatkan bahawa tumpuan promosi pelancongan di daerah Muallim dan mukim Slim adalah kepada kawasan rekreasi dan juga premis makanan. Akaun facebook Pejabat Daerah Tanah Muallim (2020b) sebagai contohnya mempromosikan Risda Eco Park di Ulu Slim. Sementara itu, dalam hantaran berhubung lawatan delegasi sejarah ke daerah Muallim, lokasi lawatan yang dikunjungi adalah Rumah Makan Muallim, Muzium Pendidikan Nasional, Rumah Za'ba, Balai Polis Tanjong Malim dan Sarang Art Hub (Pejabat Tanah Daerah Muallim, 2020a). Seterusnya, akaun Youtube Tourism Muallim (2020) dalam video promosinya kepada Muallim menyenaraikan kawasan rekreasi seperti Ujana Muallim, Gunung Liang, water rafting dan Risda Eco Resort sebagai lokasi menarik di daerah berkenaan. Ringkasnya, perhatian kepada lokasi bersejarah sejarah dalam pelancongan di mukim Slim dan daerah Muallim secara keseluruhannya masih lagi minima berbanding pelancongan pelancongan eco-tourism dan pelancongan berasaskan makanan. Pendekatan ini perlu diperbaiki kerana Exco Pelancongan Perak menyatakan bahawa, tumpuan pelancongan di Perak adalah dalam tiga jenis pelancongan iaitu pelancongan berasaskan makanan, eco-tourism dan pelancongan warisan (Awani Pagi, Disember 20, 2020). Sehubungan itu, usaha untuk memajukan pelancongan berasaskan sejarah di mukim Slim adalah selari dengan pelan kerajaan negeri dan perlu diberikan perhatian khusus oleh pihak bertanggungjawab. Inisiatif perlu diambil untuk melibatkan bukan hanya agensi kerajaan tetapi juga pihak swasta dalam usaha berkenaan. Antara pendekatannya adalah penawaran insentif kepada pihak swasta yang terlibat dalam memperkasakan pelancongan bersejarah di mukim Slim. Selain itu, pelabur juga perlu digalakkan untuk menanam modal bagi meningkatkan fasiliti di mukim Slim dan juga dalam aktiviti pelancongan seperti resort, pengangkutan dan perkhidmatan. Sokongan jitu dan kerjasama daripada semua pihak dalam melengkapkan insfrastruktur boleh membantu mukim Slim berkembang sebagai lokasi pelancongan berasaskan sejarah. Perkembangan ini akan membantu meningkat ekonomi masyarakat tempatan. Ini kerana kemasukan pelancong ke sesebuah destinasi 
mewujudkan permintaan dan penawaran terhadap aktiviti, penginapan, makanan dan minuman, perkhidmatan, kemudahan dan sebagainya. Ringkasnya, pelancongan berasaskan sejarah di mukim Slim akan membawa manafaat kepada masyarakat tempatan dan juga kerajaan negeri. Ini kerana kewujudan lokasi pelancongan baharu adalah selaras dengan polisi pentadbiran negeri Perak yang merancang untuk mempelbagaikan produk pelancongan di negeri berkenaan.

\section{Kesimpulan}

Pandemik Covid-19 membawa cabaran yang besar kepada sektor pelancongan dan ia boleh dilihat kepada penutupan hotel dan kemerosotan jumlah pelancong di Malaysia sejak pengenalan Perintah Kawalan Pergerakan di Malaysia. Justeru, sektor pelancongan memerlukan nafas baharu dalam era pasca Covid-19. Antara kaedahnya adalah melalui pengenalan destinasi baharu yang unik dan sesuai untuk pelbagai aktiviti pelancongan. Mukim Slim berpotensi untuk muncul sebagai destinasi pelancongan baharu kerana ia mempunyai pelbagai lokasi pelancongan bersejarah yang yang menarik dan tersendiri. Kekangan yang dihadapi pada masa kini adalah kewujudan tapak pelancongan bersejarah berkenaan masih belum disebarluaskan kepada masyarakat awam. Justeru, tindakan proaktif perlu diambil oleh pihak yang bertanggungjawab bagi memastikan tapak pelancongan bersejarah di mukim Slim mendapat perhatian yang sepatutnya. Maklumat berkaitan sejarah mukim Slim dan keunikannya perlu disebarkan di media sosial dan media massa. Perluasan rangkaian maklumat ini akan menyerlahkan latar belakang sejarah yang akan berfungsi sebagai agen yang memperkasakan industri pelancongan di Selatan Perak, khususnya di mukim Slim.

\section{Penghargaan}

Penulis ingin merakamkan setinggi-tinggi penghargaan dan terima kasih kepada Institut Darul Ridzuan dan Universiti Pendidikan Sultan Idris. Kajian ini dijalankan di bawah geran penyelidikan bertajuk 'Sejarah Sebagai Agen Pemerkasaan Industri Pelancongan di Daerah Muallim - Gerbang Perak Selatan’ (Kod Penyelidikan: 2017-0095-106-01).

\section{Rujukan}

$\$ 3,500,000$ to be spent on public works in Perak. (1942, September 29). Syonan Shimbun.

Adi Haji Taha. (1987). Recent archaeological discoveries in Peninsular Malaysia (1983-1985). Journal of the Malaysian Branch of the Royal Asiatic Society, 60(1 (252)), 27-44, www.jstor.org/stable/41493065

Awani Pagi; Perak Tawar lokasi pelancongan menarik. (2020, Disember 30). https://www. astroawani.com/video-terkini/awani-pagi-perak-tawar-lokasi-pelancongan-menarik-1883 531?fbclid=IwAR2ILOTB1SBvfCKlok2WA91coE9H1_xumbYAkSP8egtBaCMFwu00H qTVzRU

Badriyah Salleh. (1985). Malay rubber smallholding and British policy: A case study of Batang Padang district in Perak (1876-1952). Disertasi PhD. Fakulti Sastera dan Sains, Universiti Columbia 
Braddell, R. (1937). An introduction to the study of ancient times in the Malay Peninsula and the Straits of Malacca. Journal of the Malayan Branch of the Royal Asiatic Society, 15(3 (129)), 64-126. www.jstor.org/stable/41559897

Chinese press praises Nipponese army kindness shown during 69 day campaign in Malaya. (1942, Februari 26). Syonan Shimbun.

Deane, H. S. (1879). Survey Report on Ulu Perak. Journal of the Straits Branch of the Royal Asiatic Society, (3), 135-139. www.jstor.org/stable/41561510

Enemy infiltration in Selangor purely local. (1942, Januari 9). The Singapore Free Press and Mercantile Advertiser.

F.M.S. should survey Slim River Valley, many relics found. (1938, April 17). The Straits Times. Fong Pek Yee, (2016, April 7). An abundance of tranquility in Slim River. The Star online. https://www.thestar.com.my/metro/focus/2016/04/07/an-abundance-of-tranquillityresidents-find-peace-and-neighbourliness-in-slim-river

Gullick, J., (2010). The economy of Perak in the mid-1870s. Journal of the Malaysian Branch of the Royal Asiatic Society, $83(2$ (299)), 27-46. www.jstor.org/stable/41493778

Hamzah Jusoh, Habibah Ahmad, Amriah Buang, Nor Ghani Mohd Nor, Lelawati Ismail, Er Ah Choy, Muhammad Saiful Nizam Aduluan, \& Siti Nor Safiza Safiei. (2014). Transformasi Medan Pasar sebagai ikonik pelancongan warisan: Dimensi keperluan pengunjung dan tuntutan peniaga. Geografia-Malaysian Journal of Society and Space, 10(8), 138-153.

Jabatan Muzium Malaysia, (2018). Laporan Tahunan. https://issuu.com/webjmm7/docs/ laporan_tahunan_2018_jmm

Japs using heavier tanks now in Malaya. (1942, January 10). Malaya Tribune.

Kementerian Pendidikan. (2015). Dokumen standard kurikulum dan pentaksiran Sejarah Tingkatan 1.

Kementerian Pendidikan. (2016). Dokumen standard kurikulum dan pentaksiran Sejarah Tingkatan 2.

Kementerian Pendidikan. (2017). Dokumen standard kurikulum dan pentaksiran Sejarah Tingkatan 3.

Kementerian Pendidikan. (2018). Dokumen standard kurikulum dan pentaksiran Sejarah Tingkatan 4 dan 5.

Lee Yoke Lai, Ismail Said, \& Kubota, A. (2013). The roles of cultural spaces in Malaysia's historic town: The case of Kuala Dungun and Taiping. ASEAN Conference on Environmentbehaviour Studies. Hanoi Architectural University, Hanoi Vietnam, 19-22 Mac 2013.

Leech, H., (1879). About Slim and Bernam. Journal of the Straits Branch of the Royal Asiatic Society, (4), 34-45. www.jstor.org/stable/41560634

Majlis Daerah Tanjong Malim. (2020). Rekreasi. http://www.mdtm.gov.my/ms/pelawat/rekreasi

Mastura Jaafar, Munira Mhd Rashid, \& Norziani Dahalan (2015a). Memperkasa daya saing destinasi warisan luar bandar menerusi pembangunan perniagaan makro dan kecil: Kajian kes Lembah Lenggong. Geografia-Malaysian Journal of Society and Space, 11(2), 43-54.

Mastura Jaafar, Safura Ismail, \& S. Mostafa Rasoolimanesh. (2015b). Perceived social effects of tourism development: A case study of Kinabalu National Park. Theoretical and Empirical Researches in Urban Management, 10(2), 5-20. http://www.jstor.org/stable/24873524

Memorial to our fallen heroes at Kuala Lumpur. (1942, Ogos 28). Syonan Shimbun.

Nathan, J., (1915). A Journey over the main range from Perak to Pahang. Journal of the Straits Branch of the Royal Asiatic Society, (68), 1-5. www.jstor.org/stable/41561015

Nazirah Lee, (2018). Latar belakang Daerah Muallim. Malaysia dari segi Sejarah, 46, 66-78. 
Negeri Perak. (2016). Hala Tuju Pembangunan Negeri Perak 2040, Kajian RSN Perak 2040 (Kajian Semula) http://www.mbi.gov.my/sites/default/files/4_lp_strategi_jun.pdf

Oxford Economics. (2016). The impact of heritage tourism for the UK economy. https://www. oxfordeconomics.com/recent-releases/the-impact-of-heritage-tourism-for-the-ukeconomy

Pejabat Daerah dan Tanah Muallim. (2021). https://pdtmuallim.perak.gov.my/index.php/ informasi/latar-belakang

Pejabat Daerah Tanah Muallim. (2020b, September 21). Perak Sana Sini [status update]. Facebook https://www.youtube.com/watch?v=i3V3yKnuCR4

Pejabat Daerah Tanah Muallim. (2020a, September 5). Lawatan Delegasi Sejarah Muallim. [status update] Facebook. https://www.facebook.com/ptd.slimriver/posts/147496520270 3324

Pejabat Tanah dan Daerah Muallim. (2016). Latar belakang daerah. https://pdtmuallim.perak. gov.my/index.php/informasi/latar-belakang

Perak Government Gazette, February 1899

Perak Guidebook. (2019). https://www.tourismperakmalaysia.com/uploads/contents/TPR-19080054-PerakGuideBook_Booklet(Eng)_231019_FA.pdf

Perak Tourism (2021). Heritage. https://www.tourismperakmalaysia.com/discover/rE/heritage

Report on Tanjong Malim District for the year 1898

Report on the Batang Padang District for the year 1899

Siti Norsakira Mohamad, \& Rosniza Azmie Che Ros. (2018). Potensi bandar Kuala Lipis sebagai destinasi pelancongan warisan. Geografia-Malaysian Journal of Society and Space, 14(1), 102-115.

Slim River Battle severest so far. (1942, Januari 12). Mayborough Chronicle. https://trove.nla. gov.au/newspaper/article/152795164

Swettenham, F. (1880). From Pêrak to Slim, and down the Slim and Bernam Rivers. Journal of the Straits Branch of the Royal Asiatic Society, (5), 51-68a. www.jstor.org/stable/ 41560645

Swettenham, F. (1885). Journal kept during a journey across the Malay Peninsula. Journal of the Straits Branch of the Royal Asiatic Society, (15), 1-37. www.jstor.org/stable/41560734

Swettenham, F., (1893). About Perak. Singapore, Straits Times Press.

Tourism Muallim. (2020 Ogos 20). Vlog Muallim Eps 1: Adventure Muallim [video file] Youtube https://www.youtube.com/watch?v=i3V3yKnuCR4

Ucapan Bajet. (2017). Negeri Perak Pembentangan Rang Undang-undang Perbekalan 2017 dan membawa usul Kumpulan Wang Pembangunan 2017. http://kewangan.perak.gov.my/ images/Ucapan-Bajet-N.Perak-2017.pdf

Warren, A. (2002). Singapore 1942 Britain's greatest defeat. London, Hambledon \& London

Wilkinson, R., (1939). The Bernam Slab-Graves. Journal of the Malayan Branch of the Royal Asiatic Society, 17(1 (133)), 134-143. www.jstor.org/stable/41559939

Winstedt, R., (1935). A history of Malaya. Journal of the Malayan Branch of the Royal Asiatic Society, 13(1 (121)), iii-270. www.jstor.org/stable/41559833

Winstedt, R., (1941). Slab-Graves and iron implements. Journal of the Malayan Branch of the Royal Asiatic Society, 19(1 (138)), 93-98. www.jstor.org/stable/41559975

Winstedt, R., \& Wilkinson, R., (1934). A History of Perak. Journal of the Malayan Branch of the Royal Asiatic Society, 12(1 (118)), V-180. www.jstor.org/stable/41559831 
Yunus Sauman@Sabin, \&Wan Noorlizawati Wan Mat Ali, 2010. Kajian dan dokumentasi tapaktapak arkeologi dan tapak tanah bersejarah di Perak. Laporan Akhir Penyelidikan. GPU, Universiti Pendidikan Sultan Idris.

Zuliskandar Ramli, Mazlin Mokhtar, Mohamad Rizal Razman, \& Sharifah Zarina Syed Zakaria. (2015). Pelancongan berasaskan warisan di Malaysia: potensi dan cabaran. Prosiding Seminar Antarabangsa ke-8 Ekologi, Habitat Manusia dan Perubahan, Langkawi, 21-22 September 2015. 